\title{
Public attitudes about lung cancer: stigma, support, and predictors of support
}

This article was published in the following Dove Press journal:

Journal of Multidisciplinary Healthcare

16 July 2014

Number of times this article has been viewed

\author{
Jared Weiss' \\ Briana J Stephenson ${ }^{2}$ \\ Lloyd J Edwards ${ }^{2}$ \\ Maureen Rigney ${ }^{3}$ \\ Amy Copeland ${ }^{3}$
}

'Division of Hematology and Oncology, University of North Carolina, ${ }^{2}$ Department of Biostatistics, University of North Carolina, Chapel Hill, NC, USA; ${ }^{3}$ Lung Cancer Alliance, Washington, DC, USA
Correspondence: Jared Weiss University of North Carolina, I70 Manning Drive, Room 3II5, Campus Box 7305, Chapel Hill, NC 27599, USA

Tel +19199663856

Fax + I 9199666735

Email jared_weiss@med.unc.edu
Introduction: Lung cancer is the leading cause of cancer death, yet public engagement with efforts against lung cancer is low. Public engagement with a cancer is critical to efforts to combat it, yet the reasons for low support for efforts against lung cancer have not been systematically characterized.

Methods: We conducted a telephone survey of 1,071 people to determine levels of engagement and attitudes that might potentially drive engagement. These were then analyzed by univariate and multivariate analysis.

Results: Eight percent of participants were involved with a lung cancer organization and $12 \%$ chose it among cancers to receive more support. Most participants felt that lung cancer was principally caused by external factors, that it could be cured if caught early, and that lung cancer patients were at least partly to blame for their illness. In multivariate analysis, participants who were supportive in some way of efforts against lung cancer were more likely to be employed, live in suburbia, and to be unsure of the cause of lung cancer. Potential supporters were more likely to be employed, female, younger, have higher income, to believe that genetics is the primary cause of lung cancer, and to believe that lung cancer can be cured when caught early. Participants frequently noted that they supported a particular cancer because of knowing someone affected by that cancer.

Conclusion: As the lung cancer movement attempts to grow and increase its impact, the most successful recruitment efforts will be targeted to these groups.

Keywords: stigma, advocacy, lung cancer

\section{Introduction}

Lung cancer is the second most common cancer for both men and women, accounting for $13 \%$ of all new cancers. The American Cancer Society estimates that in 2014, 224,210 new cases of lung cancer will be diagnosed. ${ }^{1}$ They estimate that 159,260 people will die from lung cancer. At $27 \%$ of cancer deaths, lung cancer is expected to remain the leading cause of cancer death, with more people dying of lung cancer than of colon cancer, breast cancer, and prostate cancer combined. ${ }^{1}$ In addition to its high mortality, lung cancer also causes a substantial burden of suffering before death. ${ }^{2}$ As a consequence, one might expect high rates of funding for lung cancer research, but lung cancer remains a substantially underfunded cancer. In 2013, the National Institute of Health spent US\$281 million for colorectal cancer research, \$657 million for breast cancer research, and \$286 million for prostate cancer research. ${ }^{3}$ Despite dramatically higher mortality, ${ }^{1}$ lung cancer received less funding than each of these cancers at \$208 million. When rephrased as funding per death, lung cancer is even 
more underfunded - per death, $\$ 1,337$ will be invested in improving lung cancer care in 2014 compared to $\$ 5,725$ for colorectal cancer, $\$ 16,850$ for breast cancer, and $\$ 9,973$ for prostate cancer. ${ }^{1,3-6}$

Low public support for lung cancer is not restricted to funding, but can also be seen in popular perceptions and attitudes - lung cancer is highly stigmatized. ${ }^{7}$ The US Health Resources and Service Administration, in summarizing the literature on the most stigmatized illnesses, described them as sharing the following characteristics: ${ }^{8}$

- The person with the disease is seen as responsible for having the illness.

- The disease is both progressive and incurable.

- The disease is not well understood among the public.

- The symptoms cannot be concealed.

While popularly perceived within the lung cancer community, this stigma has been poorly studied in lung cancer until very recently. ${ }^{7,9}$ In other stigmatized diseases, such as human immunodeficiency virus/acquired immunodeficiency syndrome (HIV/AIDS) and obesity, stigma has been shown to negatively affect patients and health outcomes. ${ }^{10}$ Qualitative research in lung cancer suggests similar effects on the lung cancer patient. ${ }^{11,12}$ Further, public attitudes shape the level of the public's engagement with efforts against a cancer and public engagement can provide vital support to efforts to improve patient outcomes. For example, this support can include volunteerism, patient and research advocacy, support for clinical research initiatives (such as research biopsies), and support for research funding. Efforts against lung cancer greatly need this support and engagement.

Some work has explored clinicians' attitudes towards lung cancer and patients' experience, ${ }^{13-15}$ but until very recently, little work evaluated the general public's level of support or attitudes. ${ }^{9,16}$ Smoking is a common cause of lung cancer. Smoking itself is stigmatized ${ }^{17}$ and the association between smoking and lung cancer likely contributes to the stigmatization of the patient with smoking-associated cancer, ${ }^{14,18}$ regardless of whether the patient smoked. ${ }^{19}$ Therefore, it is of interest whether smoking influences the views of the general public.

In an effort to better understand public attitudes regarding lung cancer, the Lung Cancer Alliance (a lung cancer advocacy organization) surveyed 1,071 adults regarding their awareness of both lung cancer and other common cancers, their attitudes on lung cancer, and their level of support for efforts against lung cancer. The results were meaningful to the ongoing dialogue on this subject, and also created an opportunity to develop a predictive model for factors resulting in support for efforts against lung cancer. The
Lung Cancer Alliance therefore partnered with academic investigators to rigorously analyze this data and develop predictive models; the results presented herein are the products of that collaboration. Parts of this work were previously presented at the 15 th World Conference on Lung Cancer. ${ }^{20}$

\section{Materials and methods Participants}

Participants were required to not be cancer patients, cancer survivors, or caretakers of cancer patients. They were selected using a random digit dial sample provided by Survey Sampling International, Shelton, CT, USA. Interviewing was conducted among a random cross-section of American adults. Participants were required to be at least 21 years of age. The survey was entirely conducted in the United States of America.

\section{Survey}

Telephone interviews were conducted by 75 interviewers from Russell Research (a market research company) between June 24, 2008 and July 20, 2008. The survey consisted of 26 questions and the average length of the survey was 15 minutes. The survey was designed by Zeno Group (a health communications agency) with extensive input from the Lung Cancer Alliance.

\section{Conduct of the study}

Funding for the study was provided by an unrestricted grant from AstraZeneca; AstraZeneca had no role in the design, procedures, analysis, or write up of these results. The contractor Zeno Group designed the study with input from Lung Cancer Alliance, and Russell Research (a market research firm) conducted it. Subjects were told "We are conducting a study to find out people's views on various medical conditions and would like to ask you a few questions. The survey will only take about 10 minutes of your time. All answers will be kept strictly confidential." Subjects were neither promised nor given any incentive for their participation. All data were fully de-identified and are reported and analyzed only in the aggregate. The data were analyzed and this publication was prepared by Jared Weiss and Briana Stephenson.

\section{Analysis}

Univariate analysis was conducted on demographic data. Differences amongst groups were determined using two sample $t$-tests for continuous variables and chi-square tests for categorical variables. Levels of support of lung cancer research were categorized into three binary outcomes, derived from survey responses: non-supporter, potential supporter, 
and global supporter. Non-supporters were split into two types: strong and weak. Strong non-supporters were defined as any person who indicated that they were likely to support a cancer organization, but not likely to support lung cancer in the future. Weak non-supporters were defined as any person who indicated that another cancer organization should receive stronger support, as opposed to a lung cancer organization. Potential supporters were defined as any person who indicated that they do not currently support, donate, or volunteer for lung cancer organizations, but would potentially in the future. Global supporters were defined as any person who indicated that they currently contribute and volunteer time towards lung cancer organizations, would potentially support in the future, or believe lung cancer organizations should receive stronger support for research. Self-identification, and not cut-off numbers, was used to define smoking status - current smokers were defined as people who self-identified as currently smoking and former smokers were defined as people who self-identified as previously smoking.

Factors associated with these levels of support were assessed individually using chi-square analysis and collectively using multiple logistic regression. Given the large size of the dataset, variables were initially limited conceptually, based on factors likely to contribute. Backwards selection was then executed on this hypothesis-limited dataset to only include significant factors that are associated with each outcome $(\alpha=0.05){ }^{21}$ These factors included demographics, attitudes, opinions, and beliefs indicated by the study population. All data analyses were performed with SAS 9.3 software (SAS Institute Inc., Cary, NC, USA) defined at a 0.05 significance level. Goodness of fit of each multiple logistic regression model was performed using the generalized R-squared statistic. ${ }^{22}$

\section{Results}

\section{Demographics}

The demographics of the sample are shown in Table 1. Sex was well balanced. Although Caucasians dominated the study sample, Hispanics/Latinos, African-Americans, Asian/Pacific Islanders and others participated. Forty-five percent of participants attended college and 52\% were employed. Urban, suburban, and rural residents were all well represented. Never smokers, former smokers, and current smokers were all represented.

\section{Awareness of and support for cancers}

Most participants had heard of most of the cancers $-84 \%$ had heard of breast cancer, $83 \%$ lung cancer, $78 \%$ leukemia,
Table I Demographic information of the study population

\begin{tabular}{|c|c|}
\hline Characteristic & $\begin{array}{l}\text { Participants } \\
(n=1,071)\end{array}$ \\
\hline \multicolumn{2}{|l|}{ Sex } \\
\hline Male & $494(46.1)$ \\
\hline Female & $577(53.9)$ \\
\hline \multicolumn{2}{|l|}{ Age (years) } \\
\hline $21-39$ & $222(20.7)$ \\
\hline $40-59$ & $460(43.0)$ \\
\hline$\geq 60$ & $389(36.3)$ \\
\hline \multicolumn{2}{|l|}{ Ethnicity } \\
\hline Caucasian & $769(71.8)$ \\
\hline Hispanic/Latino & $135(12.6)$ \\
\hline African-American & $103(9.6)$ \\
\hline Asian/Pacific Islander & $35(3.3)$ \\
\hline Other & $2 \mathrm{I}(2.0)$ \\
\hline \multicolumn{2}{|l|}{ Education } \\
\hline High school & $437(40.8)$ \\
\hline College & $487(45.4)$ \\
\hline Postgraduate & $125(11.7)$ \\
\hline \multicolumn{2}{|l|}{ Employment } \\
\hline Unemployed & $506(47.3)$ \\
\hline Employed (part time/full time) & $559(52.2)$ \\
\hline \multicolumn{2}{|l|}{ Residence area } \\
\hline Suburban & $423(39.5)$ \\
\hline Urban & $295(27.5)$ \\
\hline Rural & $326(30.4)$ \\
\hline \multicolumn{2}{|l|}{ Household size } \\
\hline One & $24 I(22.5)$ \\
\hline Two & $371(34.6)$ \\
\hline Three & $171(16.0)$ \\
\hline Four & $164(15.3)$ \\
\hline Five & $80(7.5)$ \\
\hline Six or more & $44(4.1)$ \\
\hline Household income $<$ US $\$ 50,000$ & $399(37.3)$ \\
\hline Married & $633(59.1)$ \\
\hline Children in home & $387(36.1)$ \\
\hline \multicolumn{2}{|l|}{ Smoker } \\
\hline Never & $478(44.7)$ \\
\hline Former & $403(37.7)$ \\
\hline Current & $189(17.7)$ \\
\hline \multicolumn{2}{|l|}{ Second-hand smoke exposure } \\
\hline Yes & $911(85.1)$ \\
\hline No & $154(14.4)$ \\
\hline Don't know/not sure & $6(0.5)$ \\
\hline
\end{tabular}

Note: Table entries are $\mathrm{n}(\%)$.

$79 \%$ prostate cancer, $74 \%$ ovarian cancer, $71 \%$ colorectal cancer, $74 \%$ brain cancer, $72 \%$ liver cancer, $67 \%$ uterine cancer, and $72 \%$ pancreatic cancer. Despite this high awareness, involvement in any cancer organization was just 32\% (involvement in specific cancer-related organizations and likelihood of becoming involved are shown in Figure 1). Support was greatest for breast cancer - $18 \%$ were involved in a related organization, 29\% said that they were extremely likely or very likely to donate money or volunteer time in the future, and $25 \%$ chose it among cancers to receive 


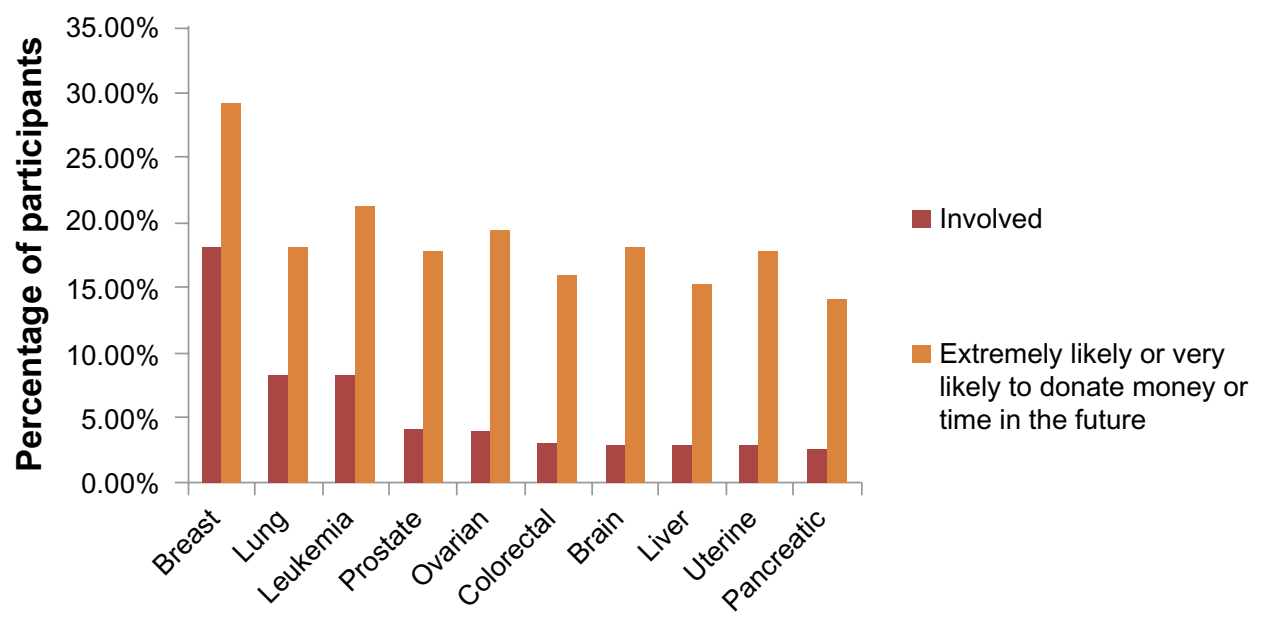

Figure I Participant involvement or potential involvement in cancer support organizations.

Notes: In red is the proportion of interviewees currently involved with a related organization. In orange is the proportion of interviewees who reported that they are extremely likely or very likely to donate money or time in the future.

more support in the future (Figure 2). In contrast, only $8 \%$ were involved with a lung cancer organization, $18 \%$ were extremely or very likely to donate money or volunteer time in the future, and $12 \%$ chose it among cancers to receive more support in the future.

\section{Attitudes on cause}

Seventy-eight percent of participants said that lung cancer is caused by external factors compared to biologic factors; responses were similar between former smokers and nonsmokers. When the question was rephrased as "environmental or genetics factors" versus "lifestyle choices", there was slightly more difference $-62 \%$ of current smokers, $64 \%$

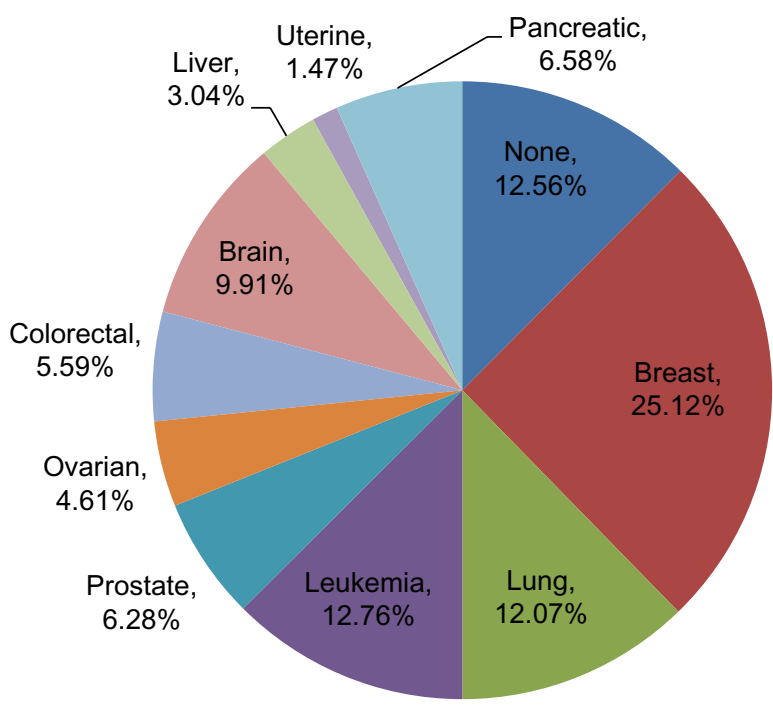

Figure 2 Subject responses to the question of which one cancer they would choose to receive stronger support for research related to its treatment and prevention. of past smokers, and $73 \%$ of never smokers cited "lifestyle choices" as the cause of lung cancer. However, never smokers were significantly less likely to cite environmental factors as the cause at $16 \%$, compared to $23 \%$ for former smokers and $25 \%$ for ongoing smokers. Ninety-four percent of participants believed that you can still get lung cancer even if you do not smoke. Seventy-three percent believed that lung cancer can be cured if caught early. Fifty-nine percent said that lung cancer patients are at least partly to blame for their illness. Forty-two percent believed that lung cancer could be prevented if smoking were banned. Thirty-one percent endorsed the statement that lung cancer patients are treated differently than other cancer patients. Twenty-seven percent believed that lung cancer can be easily treated. Twenty-three percent believed that all lung cancer is caused by actively smoking. Eleven percent said that you will not get lung cancer if you stopped smoking.

\section{Predictors of support for lung cancer}

When examined individually, being employed, female sex, suburban residence, college education, income over $\$ 50,000$ per year, and age (with highest support peaking at age 40-49) were significant demographic characteristics in describing a global supporter for lung cancer (see Table 2). Significant demographic characteristics to describe potential supporters were being employed, white race, non-rural residence, income over $\$ 50,000$ per year, and age under 70 . Strong non-supporters were more likely to be unemployed, college educated, and earn more than $\$ 50,000$ per year. The weak non-supporter was characterized as more likely to be female, college educated, have income greater than $\$ 50,000$ per year, and to not be a current smoker. 
Table 2 Demographics stratified by support level

\begin{tabular}{|c|c|c|c|c|c|c|c|c|c|c|c|c|}
\hline & \multicolumn{6}{|c|}{ Supporters } & \multicolumn{6}{|c|}{ Non-supporters } \\
\hline & \multicolumn{3}{|l|}{ Global } & \multicolumn{3}{|c|}{ Potential } & \multicolumn{3}{|c|}{ Strong } & \multicolumn{3}{|l|}{ Weak } \\
\hline & $\begin{array}{l}\text { Yes } \\
n=493\end{array}$ & $\begin{array}{l}\text { No } \\
n=578\end{array}$ & $P$ & $\begin{array}{l}\text { Yes } \\
n=356\end{array}$ & $\begin{array}{l}\text { No } \\
n=439\end{array}$ & $P$ & $\begin{array}{l}\text { Yes } \\
n=96\end{array}$ & $\begin{array}{l}\text { No } \\
n=975\end{array}$ & $P$ & $\begin{array}{l}\text { Yes } \\
n=768\end{array}$ & $\begin{array}{l}\text { No } \\
n=123\end{array}$ & $P$ \\
\hline \multicolumn{13}{|l|}{ Independent variables } \\
\hline Employed & 57.6 & 48.1 & \# & 60.7 & 46.8 & $\dagger$ & 62.5 & 51.5 & $*$ & 53.1 & 53.7 & \\
\hline White & 10.3 & 9.0 & & 11.2 & 6.2 & $\#$ & 7.3 & 9.9 & & 9.1 & 9.8 & \\
\hline Male & 42.8 & 49.0 & $*$ & 59.6 & 53.1 & & 39.6 & 46.8 & & 43.2 & 55.3 & $*$ \\
\hline Residence & & & $*$ & & & & & & & & & \\
\hline Urban & 25.2 & 29.6 & & 27.0 & 23.0 & & 20.8 & 28.2 & & 27.0 & 26.8 & \\
\hline Suburban & 44.0 & 35.6 & & 43.8 & 38.3 & & 43.8 & 39.1 & & 39.6 & 38.2 & \\
\hline Rural & 29.2 & 31.5 & & 27.8 & 36.0 & $*$ & 33.3 & 30.2 & & 30.7 & 31.7 & \\
\hline Level of education & & & $*$ & & & & & & & & & \\
\hline High school & 37.5 & 44.2 & & 35.7 & 41.0 & & 26.0 & 42.6 & & 37.3 & 47.9 & \\
\hline College & 16.5 & 12.8 & & 17.7 & 12.4 & & 21.8 & 13.8 & $\#$ & 16.5 & 7.4 & $*$ \\
\hline Postgraduate & 46.0 & 43.0 & & 46.6 & 46.5 & & 52.1 & 43.6 & & 46.2 & 44.6 & \\
\hline Income $>$ US $\$ 50,000$ & 58.6 & 47.6 & $\dagger$ & 61.3 & 50.3 & $\#$ & 68.3 & 51.2 & $\#$ & 56.3 & 43.1 & $*$ \\
\hline Age (years) & & & $\#$ & & & & & & & & & \\
\hline $21-29$ & 8.9 & 8.7 & & 9.8 & 6.8 & & 14.6 & 8.2 & & 9.4 & 7.3 & \\
\hline $30-39$ & 13.8 & 10.4 & & 15.2 & 8.4 & & 11.5 & 12.0 & & 13.8 & 7.3 & \\
\hline $40-49$ & 22.5 & 19.6 & & 23.0 & 16.4 & & 21.9 & 20.8 & & 20.1 & 22.8 & \\
\hline $50-59$ & 20.9 & 23.0 & & 21.6 & 23.5 & & 22.9 & 22.0 & & 21.1 & 23.6 & \\
\hline $60-69$ & 19.5 & 16.3 & & 19.7 & 20.7 & & 16.7 & 17.9 & & 18.6 & 18.7 & \\
\hline$\geq 70$ & 14.4 & 22.2 & & 10.7 & 24.0 & $\dagger$ & 12.5 & 19.2 & & 17.1 & 20.3 & \\
\hline Current smokers $(\mathrm{n}=189)$ & 19.5 & 16.1 & & 19.7 & 17.5 & & 12.5 & 18.2 & & 16.3 & 27.6 & \# \\
\hline Previous smokers $(n=403)$ & 49.2 & 42.9 & & 46.0 & 48.3 & & 45.2 & 45.8 & & 46.1 & 50.6 & \\
\hline Average years quit smoking & 5.8 & 6.2 & & 5.8 & 6.1 & & 6.0 & 5.7 & & 6.0 & 5.7 & \\
\hline
\end{tabular}

Notes: Table entries are percentage or mean values. ${ }^{\dagger} P<0.000$ I, refers to income; ${ }^{*} P<0.0$ I, refers to age; $* P<0.05$, refers to level of education. All other $P$-values not indicated were greater than 0.05 .

Attitudes on primary causes of lung cancer were significant indicators of support type. Global supporters were more likely to believe genetics was a primary cause of lung cancer. Uncertainty of the primary cause was a significant factor in describing all groups other than strong non-supporters (Table 3). Strong non-supporters are the only group that believed that lung cancer could be prevented if smoking were banned. Weak non-supporters were more likely to believe that lung cancer was caused by lifestyle choices or external factors.

Multivariable logistic regression revealed three significant factors associated with being a lung cancer supporter (Table 4). Employed persons were 49\% more likely to be a global supporter than unemployed persons. Suburbanites were $40 \%$ more likely than urban or rural dwellers to be a global supporter. Those who weren't sure of the primary cause of lung cancer were $69 \%$ more likely to be a global supporter than those who were sure. In contrast, those who believed that smoking should be banned were $60 \%$ more likely to be a strong non-supporter and those who made more than $\$ 50,000$ per year were nearly twice as likely to be a strong non-supporter. The potential supporter was characterized as employed ( $54 \%$ more likely to be a potential supporter), female (men were almost half as likely to be a potential supporter), younger in age (odds of being a potential supporter decreased with each new age bracket), and make more than $\$ 50,000$ per year. Those who believed that genetics was the primary cause of lung cancer were $80 \%$ more likely to be a potential supporter and those who believed that lung cancer can be cured when caught early were $66 \%$ more likely to be potential supporters.

We also asked participants directly why they favored stronger research support for the cancer that they chose to receive more support. Across the cancers supported, the greatest reason for support was knowing someone who had the relevant cancer. Other relevant factors included a belief that the cancer might affect oneself, the types of people targeted by the disease, a belief that more research needs to be done in the disease, and poor survival with the disease.

\section{Discussion}

Participants identified two factors specifically associated with lung cancer as important for supporting particular cancers poor survival and a need for more research on the disease. However, the greatest number of responses regarded personal interaction with a particular cancer - knowing someone 
Table 3 Attitudes/beliefs about LC stratified by support level

\begin{tabular}{|c|c|c|c|c|c|c|c|c|c|c|c|c|}
\hline & \multicolumn{6}{|c|}{ Supporters } & \multicolumn{6}{|c|}{ Non-supporters } \\
\hline & \multicolumn{3}{|l|}{ Global } & \multicolumn{3}{|c|}{ Potential } & \multicolumn{3}{|c|}{ Strong } & \multicolumn{3}{|l|}{ Weak } \\
\hline & $\begin{array}{l}\text { Yes } \\
n=493\end{array}$ & $\begin{array}{l}\text { No } \\
n=578\end{array}$ & $P$ & $\begin{array}{l}\text { Yes } \\
n=356\end{array}$ & $\begin{array}{l}\text { No } \\
n=439\end{array}$ & $P$ & $\begin{array}{l}\text { Yes } \\
n=96\end{array}$ & $\begin{array}{l}\text { No } \\
n=975\end{array}$ & $P$ & $\begin{array}{l}\text { Yes } \\
n=768\end{array}$ & $\begin{array}{l}\text { No } \\
n=123\end{array}$ & $P$ \\
\hline \multicolumn{13}{|l|}{ Attitudes/beliefs } \\
\hline Genetics is primary cause & 23.7 & 15.9 & $\dagger$ & 21.1 & 17.8 & & 22.9 & 19.9 & & 19.7 & 26.8 & \\
\hline Lifestyle is primary cause & 66.5 & 68.8 & & 69.4 & 67.0 & & 69.8 & 67.3 & & 70.5 & 57.7 & \# \\
\hline Biologic factors are primary cause & 10.6 & 11.3 & & 9.3 & 12.8 & & 11.5 & 10.8 & & 9.8 & 16.3 & $*$ \\
\hline External factors are primary cause & 76.3 & 76.0 & & 77.3 & 74.3 & & 82.3 & 75.4 & & 78.8 & 69.9 & $*$ \\
\hline $\begin{array}{l}\text { Not sure if lung cancer caused by } \\
\text { biologic or external factors }\end{array}$ & 13.2 & 8.7 & $*$ & 13.5 & 13.0 & & 6.3 & 11.2 & & 10.0 & 13.8 & \\
\hline $\begin{array}{l}\text { Not sure if lung cancer caused by } \\
\text { environmental or genetic factors, } \\
\text { or lifestyle choice }\end{array}$ & 9.7 & 10.4 & & 9.6 & 15.3 & * & 7.3 & 10.4 & & 8.6 & 15.5 & $*$ \\
\hline LC patients are partly to blame & 59.6 & 61.2 & & 56.9 & 62.9 & & 63.4 & 59.9 & & 60.4 & 66.4 & \\
\hline LC is caused by actively smoking & 23.8 & 23.0 & & 22.7 & 23.5 & & 21.9 & 23.6 & & 22.3 & 30.3 & \\
\hline LC can be cured if caught early & 81.7 & 78.8 & & 81.5 & 78.5 & & 78.0 & 80.7 & & 80.2 & 81.2 & \\
\hline LC can be prevented if smoking is banned & 42.0 & 44.4 & & 42.6 & 44.5 & & 54.7 & 41.6 & $*$ & 44.3 & 45.1 & \\
\hline LC can be easily treated & 37.0 & 35.7 & & 37.6 & 35.8 & & 39.0 & 36.1 & & 36.4 & 38.0 & \\
\hline You can get $L C$ as a non-smoker & 95.1 & 93.6 & & 94.9 & 93.6 & & 93.8 & 94.5 & & 94.8 & 94.2 & \\
\hline You won't get LC if you stop smoking & 12.0 & 11.4 & & 13.8 & 10.5 & & 12.6 & 11.6 & & 11.4 & 13.1 & \\
\hline \multicolumn{13}{|l|}{ Why should LC get more support? } \\
\hline Family member has it & 22.7 & 17.1 & $*$ & 22.7 & 17.1 & * & 24.0 & 19.3 & & 22.3 & 27.6 & \\
\hline Friend/someone I know has it & 16.8 & 8.3 & $\dagger$ & 16.8 & 8.3 & $\dagger$ & 11.5 & 12.3 & & 14.7 & 13.0 & \\
\hline It affects me (self) & 9.9 & 6.9 & & 9.9 & 6.9 & & 12.5 & 7.9 & & 9.5 & 11.4 & \\
\hline
\end{tabular}

Notes: Table entries are percentage. ${ }^{\dagger} P<0.0001 ;{ }^{*} P<0.01 ; * P<0.05$. $P$-values for categorical variables (residence, education, and age) refer to overall group differences according to a chi-squared test.

Abbreviation: LC, lung cancer.

Table 4 Predictors of support for or against lung cancer

\begin{tabular}{|c|c|c|}
\hline & Odds ratio & $95 \% \mathrm{Cl}$ \\
\hline \multicolumn{3}{|l|}{ Outcome: strong non-support } \\
\hline $\begin{array}{l}\text { Believes that lung cancer could be } \\
\text { prevented if smoking were banned }\end{array}$ & 1.60 & $(1.00,2.56)$ \\
\hline$>$ US $\$ 50,000$ per year & 1.96 & $(1.19,3.22)$ \\
\hline \multicolumn{3}{|l|}{ Number of observations: 696} \\
\hline \multicolumn{3}{|l|}{ Generalized $R^{2}=0.0149$} \\
\hline \multicolumn{3}{|l|}{ Outcome: potential support } \\
\hline Employed & 1.54 & $(1.04,2.28)$ \\
\hline Male & 0.56 & $(0.39,0.79)$ \\
\hline Age & 0.84 & $(0.73,0.95)$ \\
\hline Income $>$ US $\$ 50,000$ per year & 1.44 & $(1.01,2.06)$ \\
\hline Genetic & 1.80 & $(1.16,2.80)$ \\
\hline $\begin{array}{l}\text { Believes that lung cancer can be cured } \\
\text { if caught early }\end{array}$ & 1.66 & $(1.06,2.59)$ \\
\hline \multicolumn{3}{|l|}{ Number of observations: 577} \\
\hline \multicolumn{3}{|l|}{ Generalized $R^{2}=0.0703$} \\
\hline \multicolumn{3}{|l|}{ Outcome: global support } \\
\hline Employed & 1.49 & $(1.16,1.91)$ \\
\hline Suburb & $\mathrm{I} .40$ & $(1.09,1.79)$ \\
\hline $\begin{array}{l}\text { Not sure about the primary cause of } \\
\text { lung cancer }\end{array}$ & 1.69 & $(1.13,2.54)$ \\
\hline \multicolumn{3}{|l|}{ Number of observations: 1,042} \\
\hline Generalized $R^{2}=0.0208$ & & \\
\hline
\end{tabular}

Note: Adjusted odds ratios derived from multiple logistic regression.

Abbreviation: $\mathrm{Cl}$, confidence interval. affected was the most common response, followed by a belief that one might be affected oneself. Notably, the cancer with greatest support was breast cancer, the most incident cancer in women. However, the association with incidence was poor as prostate cancer (the most incident cancer in men) and colon cancer (the third most incident cancer in each sex) also received low levels of support. Participants noted that the type of people affected by the disease was important; here, the stigmatization of lung cancer might have negatively influenced support.

Research presented concurrently with the analysis of this dataset shed significant light on the stigmatization of the lung cancer patient. Schiller et al investigated the explicit and implicit attitudes of the general public, health care providers, people with cancer, and their providers regarding both lung cancer and breast cancer. ${ }^{9}$ Relative to breast cancer, all groups, including the general population, demonstrated significant negative attitudes towards lung cancer. If the type of people affected by a disease influences public support for it, then the negative views of the lung cancer patient demonstrated by Schiller et al's work would be expected to negatively influence support. In addition to 
direct questioning, we also utilized multivariate analysis to look for other factors predicting current support for lung cancer; while three reached statistical significance (employment, living in suburbia, and being unsure of the cause of lung cancer), none were powerful predictors.

Attitudes on primary causes of lung cancer were significant indicators of support type in univariate analysis (Table 3) in a fashion that is consistent with attribution theory. Attribution theory predicts that when a condition is caused by a factor that is under the control of the affected person, it is more likely to be stigmatized. ${ }^{17}$ Here, strong non-supporters were more likely to believe that lung cancer could be prevented if smoking were banned, while global supporters were more likely to believe that genetics was a primary cause of lung cancer. These findings suggest that efforts by advocacy organizations to educate the public about non-smoking-related causes of lung cancer might increase support. Further, education about external causes of smoking, such as social stress and inherited vulnerability to nicotine addiction, might help to decrease the stigma of lung cancer and increase support for efforts against it.

There are several important weaknesses to this work. The study was designed in the context of market research, without academic consultation. Therefore, no psychometric validation of the study was performed and the conduct of the study was not reviewed by a protocol review committee or investigational review board. The study was conducted only in the US and may not be generalizable to other areas of the world. No attempt was made to ensure that a representative population of the US was obtained. While the large number of participants surveyed might somewhat ameliorate this problem, the demographics, as seen in Table 1 are not fully representative of the US population. Finally, the study addresses the attitudes of the general population, but not those of patients or oncologists. We have conducted surveys of lung cancer patients and of oncologists who treat lung cancer and the results will be the subject of future reports. Further, despite these limitations, the study is large and well-powered to address drivers behind support, or lack of support, for efforts against lung cancer.

The breast cancer story teaches us that attitudes on cancers can change. ${ }^{23}$ Breast cancer was once highly stigmatized and rarely discussed in public. In 1974, former first lady Betty Ford was diagnosed with breast cancer and she chose to discuss it publicly. In 1982, after Susan G Komen died of breast cancer, her sister founded the organization that bears her name. In 2013, women with breast cancer marched proudly, soup cans bore pink ribbons, and breast cancer was discussed openly. This change in attitudes regarding breast cancer has had tangible effects on efforts to reduce the burden of suffering from breast cancer. While any cancer diagnosis is challenging, the breast cancer patient in 2014 suffers from dramatically less stigma. Advocacy, education, volunteerism, support for involvement with clinical studies, and research funding for breast cancer are strong. In contrast, while advocacy for lung cancer has made modest gains, stigma remains prominent, funding for research low, and support for research efforts limited. Awareness of this situation is limited - almost twice as many participants in our study (59\%) believed that lung cancer patients were at least partly to blame for their cancer than recognized that lung cancer patients are treated differently from other types of patients (31\%). Lung cancer advocacy organizations are already fighting stigma, educating the public, supporting clinical trials, and working to increase funding for lung cancer research. As these organizations grow, they will need to recruit new members. While anyone passionate about lung cancer can help, recruitment efforts are most likely to be successful when addressed towards those who have already been touched in some way by lung cancerlung cancer survivors, the loved ones of those affected by lung cancer, and lung cancer professionals. Potential supporters are more likely to know someone affected by lung cancer, be employed, be female, be younger, have higher income, recognize causes of lung cancer other than smoking, and believe that lung cancer is treatable.

\section{Disclosure}

Parts of this work were previously presented at the 15th World Conference on Lung Cancer. ${ }^{20}$ This work was supported by AstraZeneca. Lloyd Edwards was supported by the National Center for Research Resources and the National Center for Advancing Translational Sciences, National Institutes of Health, through Grant Award Number UL1TR000083. The authors have no other conflicts of interest in this work.

\section{References}

1. What are the key statistics about lung cancer? [webpage on the Internet] Atlanta: American Cancer Society; 2014. Available from: http://www. cancer.org/cancer/lungcancer-non-smallcell/detailedguide/non-smallcell-lung-cancer-key-statistics. Accessed March 28, 2014.

2. Kotajima F, Kobayashi K, Sakaguchi H, Nemoto M. Lung cancer patients frequently visit the emergency room for cancer-related and -unrelated issues. Mol Clin Oncol. 2014;2(2):322-326.

3. NIH Research Portfolio Online Reporting Tools: Estimates of Funding for Various Research, Condition, and Disease Categories (RCDC) [webpage on the Internet]. Bethesda: National Institutes of Health; 2014. Available from: http://report.nih.gov/categorical_spending.aspx. Accessed June 11, 2014. 
4. What are the key statistics about breast cancer? [webpage on the Internet]. Atlanta: American Cancer Society; 2014. Available from: http:// www.cancer.org/Cancer/BreastCancer/DetailedGuide/breast-cancerkey-statistics. Accessed March 28, 2014.

5. What are the key statistics about colorectal cancer? [webpage on the Internet]. Atlanta: American Cancer Society; 2014. Available from: http://www.cancer.org/cancer/colonandrectumcancer/detailedguide/ colorectal-cancer-key-statistics. Accessed March 28, 2014.

6. What are the key statistics about prostate cancer? [webpage on the Internet]. Atlanta: American Cancer Society; 2014. Available from: http://www.cancer.org/Cancer/ProstateCancer/DetailedGuide/prostatecancer-key-statistics. Accessed March 28, 2014.

7. Chambers SK, Dunn J, Occhipinti S, et al. A systematic review of the impact of stigma and nihilism on lung cancer outcomes. BMC Cancer. 2012;12:184.

8. HIV/AIDS Stigma [webpage on the Internet]. New York: The Body; 2003; http://www.thebody.com/content/art12405.html. Accessed April 19, 2013.

9. Schiller JH, Bowden CJ, Mills J, et al. Explicit and implicit attitudes toward lung cancer (LC) relative to breast cancer (BC). J Clin Oncol. 2013;31(Suppl):Abstr 8017.

10. Sengupta S, Banks B, Jonas D, Miles MS, Smith GC. HIV interventions to reduce HIV/AIDS stigma: a systematic review. AIDS Behav. August 2011;15(6):1075-1087.

11. Conlon A, Gilbert D, Jones B, Aldredge P. Stacked stigma: oncology social workers' perceptions of the lung cancer experience. J Psychosoc Oncol. 2010;28(1):98-115.

12. Hamann HA, Ostroff JS, Marks EG, Gerber DE, Schiller JH, Lee SJ. Stigma among patients with lung cancer: a patient-reported measurement model. Psychooncology. 2014;23(1):81-92.
13. Cataldo JK, Jahan TM, Pongquan VL. Lung cancer stigma, depression, and quality of life among ever and never smokers. Eur J Oncol Nurs. 2012;16(3):264-269.

14. Chapple A, Ziebland S, McPherson A. Stigma, shame, and blame experienced by patients with lung cancer: qualitative study. $B M J$. 2004;328(7454):1470.

15. LoConte NK, Else-Quest NM, Eickhoff J, Hyde J, Schiller JH. Assessment of guilt and shame in patients with non-small-cell lung cancer compared with patients with breast and prostate cancer. Clin Lung Cancer. 2008;9(3):171-178.

16. Else-Quest NM, LoConte NK, Schiller JH, Hyde JS. Perceived stigma, self-blame, and adjustment among lung, breast and prostate cancer patients. Psychol Health. 2009;24(8):949-964.

17. Stuber J, Galea S, Link BG. Smoking and the emergence of a stigmatized social status. Soc Sci Med. 2008;67(3):420-430.

18. Lehto RH. Patient views on smoking, lung cancer, and stigma: A focus group perspective. Eur J Oncol Nurs. 2014;18(3):316-322.

19. Brown Johnson CG, Brodsky JL, Cataldo JK. Lung cancer stigma, anxiety, depression, and quality of life. J Psychosoc Oncol. 2014;32(1): 59-73.

20. Weiss J, Stephenson B, Edwards L, Rigney M, Copeland A. Public attitudes about lung cancer: stigma, support, and predictors of support. Paper presented at: 15th World Conference on Lung Cancer; October 27-31, 2013; Sydney, Australia

21. Muller KE, Fetterman BA. Regression and ANOVA: an integrated approach using SAS software. Cary (NC): SAS Institute; 2002.

22. Cox DR, Snell EJ. Analysis of Binary Data, Second Edition. Boca Raton: CRC Press; 1989.

23. Gulyn LM, Youssef F. Attribution of blame for breast and lung cancers in women. J Psychosoc Oncol. 2010;28(3):291-301.
Journal of Multidisciplinary Healthcare

\section{Publish your work in this journal}

The Journal of Multidisciplinary Healthcare is an international, peerreviewed open-access journal that aims to represent and publish research in healthcare areas delivered by practitioners of different disciplines. This includes studies and reviews conducted by multidisciplinary teams as well as research which evaluates the results or conduct of such teams or

\section{Dovepress}

healthcare processes in general. The journal covers a wide range of areas and welcomes submission from practitioners at all levels, from all over the world. The manuscript management system is completely online and includes a very quick and fair peer-review system. Visit http://www.dovepress.com/testimonials.php to read real quotes from published authors. 